\title{
The Influence on Need for Cognition, Web Expertise and Trust on Online and Offline Information Search Behaviour: An Abstract
}

\author{
Elfriede Penz, Agnieszka Zablocki, and Philipp Simbrunner
}

\begin{abstract}
Word of mouth (WOM) and its equivalent electronic word of mouth (eWOM) have been established as important influences in consumer decision processes. While recent research has explored the various aspects of eWOM and confirmed its importance as a source of information for consumers in online contexts (Zhu \& Zhang, 2010), no study so far has investigated simultaneously traditional WOM and offline environments and the importance of eWOM in relation to other sources of information, namely, commercial and public channels. Thus, the aim of this study is to explore these relationships and to compare consumers' online and offline information search behaviour, depending on need for cognition (NFC), web expertise and trust in offline and online sources, which are considered relevant influences to information search behaviour. Time consumers spend on a particular website is agreed as a crucial performance metric for websites (Danaher et al., 2006). Previous research suggests that usage duration better reflects consumer's engagement than loyalty or intention measures (Dholakia et al., 2004). The experimental design ( $n=366,53.27 \%$ female, $\left.M_{\text {age }}=30.23, \mathrm{SD}_{\text {age }}=11.35\right)$ consisted of an interactive online information search task. Participants were asked to gather information for a buy or no-buy decision of a high-involvement product, namely, a HDTV monitor. This direct observation of consumers' actions in a buying decision-related information search task was combined with a questionnaire focusing on their individual motives for choosing information sources (commercial, public and personal). Items measuring the need for cognition (Bless et al., 1994), web expertise, trust in and usage frequency of commercial, public and personal (online vs. offline) were used (5-point Likert scale). According to our results, consumer's decision to search for information in the online environment depends very much on web expertise and trust, not on NFC. The search itself with usage frequency and time spent, however, is not influenced by web expertise anymore, but depends mainly on trust.
\end{abstract}

\section{References Available Upon Request}

E. Penz • A. Zablocki $(\bowtie) \bullet$ P. Simbrunner

Vienna University of Economics and Business, Vienna, Austria

e-mail: elfriede.penz@wu.ac.at; agnieszka.zablocki@wu.ac.at; philipp.simbrunner@wu.ac.at 